\title{
Middle-aged Lebanese women interpretation of sexual difficulties: A qualitative inquiry
}

Mathilde Azar ( $\nabla$ mathilde.azar@balamand.edu.lb )

University of Balamand Faculty of Health Sciences https://orcid.org/0000-0003-3127-746X

\section{Caroline Bradbury-Jones}

University of Birmingham

\section{Thilo Kroll}

University College Dublin

\section{Research article}

Keywords: Women, sexual difficulties, qualitative research, marital relation, context, middle-age

Posted Date: August 21st, 2020

DOl: https://doi.org/10.21203/rs.3.rs-24251/v2

License: (1) This work is licensed under a Creative Commons Attribution 4.0 International License. Read Full License 


\section{Abstract}

Background: The study explores women's perception and experience of sexual difficulties. The need to address the subject was triggered by the scarcity of research that reflects on women's subjective views on sexual difficulties. This is particularly crucial for middle-aged women who frequently experience hormonal and psychosocial changes that may affect their sexual life.

Methods: Using in-depth individual and focus groups interviews, 52 Lebanese women aged 40-55 years discussed their thoughts, feelings and behaviours concerning sexual difficulties. In respect to ethical principles, women were recruited purposefully from clinical and non-clinical settings to get maximum sampling variation that provided rich information and deep understanding of the subject. Recordings were transcribed verbatim and analyzed about the framework analysis. Many strategies were adopted to ensure rigour.

Results: Women's narratives led to four themes: women's inability to communicate sexual desires and concerns; male-related sexual difficulties; marital conflicts; and sexual difficulties as context bound. Women's sexual difficulties are driven by double standards and inhibiting sexual socialization. Once married, many women had very challenging sexual experiences. They were obliged to silently bear their husbands' poor sexual performance to protect their masculinity and thus their social image and identity. Women's narratives also showed that marital conflicts, daily life problems as well as physical and psychological burdens further challenged their sexual wellbeing and contributed to their sexual difficulties.

Conclusion: The study makes a unique contribution to voicing women's views and concerns as sexuality is underreported and poorly researched in Lebanon. It corroborates the multidimensional nature of female sexual difficulties, particularly the gender-based norms that inhibit their sexual selves and profoundly affect their sexual wellbeing and capacity to claim their sexual likes and dislikes. Findings have implications on research and practice to help women prevent and overcome their sexual difficulties.

\section{Plain English Summary}

This study explored middle-aged Lebanese women's views and experiences about sexual difficulties. Using face-to-face interviews, women had the opportunity to voice their concerns and talk openly about the way they understand their sexual difficulties. Findings showed that women do not talk about their sexual difficulties in terms of how their bodies function. Sexuality and sexual concerns are affected by many aspects of women's lives, Lebanese culture and their relationships with husbands/partners. Some women lacked awareness about their sexual needs and rights. Shyness, intimidation and lack of knowledge compromise their enjoyment of sex. For many, sexual life remains a taboo subject. Many of them were sexually inexperienced when they got married. Most had sex for the first time with their husband. Sex is perceived as 'forbidden' outside marriage. The women reported painful experiences that affected their sexual desire and interest. For some, the insensitivity and inexperience of their husbands 
as well their husbands' impaired sexual performance e.g. problems with maintaining an erection prevented them from enjoying sex. This was made even worse as many husbands were reluctant to seek professional help fearing disclosure of their problems to strangers and negative impact on their masculinity. Facing marital conflicts and lacking love and respect, many women were victims of forced sex or were doing it as a duty. Moreover, daily life stressors and chores further caused sexual difficulties. As sexuality is an essential component of overall wellbeing, women should recognize and discuss their sexual difficulties to manage them and enjoy their sexual life.

\section{Background}

Satisfying sexual experiences throughout the life course are linked to perceptions of a good quality of life and general wellbeing [1, 2], but with age, sexual functioning and satisfaction may change [3]. For women, the transition to menopause constitutes a significant physical and psychosocial challenge at middle-age. From a biomedical perspective, the literature abounds with epidemiological studies about different forms of female sexual disorders affecting women across cultures and age groups $[4,5,6]$ in both developed and developing countries $[7,8,9]$. Sexual problems increase three folds in the climacteric [10] and are 2.3 times more likely to happen from pre to post-menopause [11]. The prevalence is $41 \%$ worldwide among reproductive-age women [McCool et al., 2014]; it rises further among postmenopausal women to reach $68 \%$ to $86.5 \%$ [12].

A systematic review of one hundred thirty-five quantitative studies from 41 countries identified a multitude of factors that predict female sexual problems confirming their multidimensional nature [13]. The review also revealed some protective factors such as having an intimate relationship and communication, getting married at an older age, being sexually educated and having a favorable body image. Women's sexual function is also affected by the different standards of sexual conduct that are still pervasive in contemporary societies, including Lebanon. The Global Study of Sexual Attitudes and Behaviors (GSSAB) that surveyed 27,500 men and women in 29 countries showed that among sexually active participant, $43 \%$ of men and $49 \%$ of women reported experiencing at least one sexual problem during the last 12 months [14]. Women scored less than men in their sexual wellbeing [15; 16]. In the male-centred regimes as defined by Laumann and colleagues [15], the rate of women's satisfaction with sexual functioning was at $39.7-61.3 \%$, whereas this rate was at $64.4-91.1 \%$ in gender-equal regimes.

Studies concerning the effect of hormonal decline and ageing on women's sexual functioning are controversial. Indeed, some aspects of women's sexual functioning may decline or worsen with ageing and reduction of hormonal production $[17,3,18]$. But whether and how these changes affect women depends mainly on the way they are perceived [19]. For instance, it is not sure that menopausal changes inexorably affect sexual desire. With ageing, many women report better sexual functioning [20, 21], an increased frequency of orgasm during intercourse and the number of those who claimed never having had an orgasm decreased 22, 23, 24]. A study by Berra and colleagues [25] also revealed that menopausal women $(36.2 \%)$ are less distressed by sexual dysfunction in comparison with premenopausal women (64.5\%). 
Moreover, for some women, a low sexual desire did not cause distress in the menopausal transition and did not threaten their relationship with the partner [26]. Anxiety during sex declined with ageing [17]. However, other women reported negative impacts of menopause on their interpersonal relationships, marital intimacy, satisfaction and stability that may lead to divorce $[26,27]$. A satisfying sexual life, on the other hand, strengthens couples' marital bonds [28].

Female sexual dysfunction as generated by the Diagnostic and Statistical Manual of Mental Disorders, $[29,30]$ has creed a great debate and reflected a lack of consensus on the conceptualization of this construct. Adding to that, epidemiological studies have faced several methodological limitations [31, 32]. The samples are mostly drawn from clinical settings and do not consider the general population and women of different age groups. The instruments used to identify sexual problems focus predominantly on biomedical aspects with less consideration to women's subjective view and conceptualization of these problems.

Since female sexuality is a multifaceted construct, it has to be considered in the context of women's lives, their experiences, values and beliefs, and the quality of their relationships in addition to biological, psychosocial and economic factors [26, 27].

Over the past decades, increasing interest has been accorded to qualitative research that represents women's insights and experiences of sexuality and perception of sexual difficulties. But, few of them have focused on sexual difficulties of the middle-aged women. Studies conducted in the middle-East with different samples of women reported one or more sexual problems with a prevalence rate ranging between $26-81.5 \%[33 ; 34 ; 35 ; 36 ; 37 ; 38)$. A comparative study conducted among a representative sample of women aged 45-55 years from Lebanon, Morocco, Spain and the United States did not depict an association between menopausal status and sexual symptoms. Yet, a positive association was identified with age [39]. However, the prevalence of sexual symptoms (59\%) was the highest among Lebanese women.

Data generated from these epidemiological studies are indispensable to inform practice and offer appropriate services. In the Middle-East and Lebanon in particular, very little research has been conducted to understand sexual life from the perspective of women. As reported by Maaita and colleagues [38], in Arabic societies, talking about sexual disorders is very sensitive and may lead to inaccurate and noncomprehensive results. In Lebanese culture, sexuality and sexual concerns are still taboo subjects, especially for the middle-aged and older generation. At this age, there is still a tendency to position women as asexual. Sexual difficulties are neither discussed publicly nor privately. Healthcare providers seldom discuss the subject with their patients. Just like men, women rarely seek help for sexual difficulties, probably because they are unaware of the nature of their problems or simply feel ashamed. Just like in other parts of the world, Lebanese women view sexuality vital for marital stability [40]. Thus, women face the challenge of navigating the tension between maintaining a satisfying sexual life and staying silent on the issue should sexual difficulties arise. 
It may not be surprising that sexuality is under-researched and not visible as a topic in the Lebanese health care context. This paper contributes to opening up the discourse on sexuality and sexual concerns. It aims to explore middle-aged Lebanese women's perception and experience of sexual difficulties and the way these difficulties are shaped in relation to the male-centred sexual interactions and social norms.

An improved understanding of the sociocultural aspects of these experiences will provide critical information for healthcare professionals to engage with women purposefully about their sexuality and related concerns.

\section{Methods}

\section{Research design}

This paper that aims to explore women's construction of their sexual difficulties is part of a series of qualitative research including different phases where one phase informed the other and provided a comprehensive understanding of women's sexuality. . This naturalistic and holistic paradigm guided by an interpretive and inductive process is well suited to explore sexuality, which is a complex, tacit, sensitive and no well-known topic [41]. It allows researchers to gain deep insights into women's thoughts, feelings, attitudes and experiences concerning sexual difficulties as grounded in the Lebanese context.

\section{Research setting and participants}

In this study, the sample was recruited from clinical and non-clinical settings. The clinical settings included mammography units of two university hospitals, one private and one public and three outpatient clinics. The non-clinical settings included two organizations, a journalism agency and a business center. The variation in the settings was suggested to optimize heterogeneity and enrich data generation [42]. The access to the participants required the approval of the administrators of the chosen settings. The first investigator of the study was involved in the recruitment process. She met the potential participants identified by the administrative personnel of the settings, provided them with information about the study in writing and orally. She answered all their questions and gave them time to make their decision. Those who participated in the study deliberately consented to be interviewed after having carefully read an informed consent and understood all the information related to their involvement in the study and the ethical considerations. In line with other researchers' observations [43, 44], the recruitment process was long and difficult as some women were hesitant to reflect on their sexual life in view of the sensitivity of the topic.

Women were selected purposively by level of education and menopausal status, acknowledging their implication in the perception and experience of sexuality $[45,46]$. Marital status, religion and occupation were also collected and considered in the research objectives, data analysis and interpretation as they enriched findings. Snowball sampling was added due to difficulties in identifying eligible women and the sensitivity inherent to sexual disclosure. This included only eight women who were selected with a reflective manner to represent different views and avoid compromising the heterogeneity of the sample 
[47]. Women who participated in the study were 40-55 years old, Lebanese and spoke Arabic, regardless of their marital status and sexual orientation. Women were asked about the perception of their health and if they complain of any health problem. Those who declared having acute (sudden and severe health problem) or chronic physical and mental health problems (non-controlled diabetes, hypertension, heart disease, cancer, depression, etc.) at the time of the interviews were excluded. Their health condition may interfere with the perception and experience of sexuality, adding another layer of complexity to the interpretation of findings [48]. Data saturation was determined to be reached when no new or conflicting information would arise in interviews [49,50]. This was done having in mind that thick (quantity) and rich (quality) description was provided to enhance transferability and credibility of findings $[49,50]$.

\section{Data collection}

The first author of the study (MA) conducted 37 individual interviews and three focus groups, each one composed of four to six participants. Interviews lasted between 45 and 90 minutes, and focus groups between 90 and 180 minutes. The two data collection approaches were used as a triangulation method to enhance data richness and depth of inquiry and provide a more comprehensive understanding of women's sexual difficulties [51].

A topic guide was developed with a series of open-ended questions that allowed the participants to reflect on intimate issues and voice their sexual concerns. To overcome the potential sensitivity and embarrassment about discussing sexuality, a case description and vignette were used to facilitate the conversation [52]. The participants were asked to comment on a situation that portrays a 49 old woman who was interviewed within a programme of women's health about her sexual health issues. The questions reflected on her attitude and experience towards the disclosure of sexual problems and sexual changes and difficulties that may happen around the menopausal period. The vignette provided an introduction to the study and prompted participants to reflect on their own experiences. This facilitated the conduct of the subsequent interviews. The first author is qualified in reproductive health and who is immersed in the Lebanese culture promoted communication with women. This allowed her to get a shared understanding of their thoughts and values [53]. The majority of the interviews were carried out at the workplace of the researcher. This happened in a private and comfortable environment to allow the participants to easily express themselves. The main questions were focused on what women consider to be a sexual problem and their experience with this. Prompts were used to stimulate women to talk, such as: What words or phrases come to mind that are synonymous with sexual problems for you? What might be the factors that relate to women's sexual problems? What would you consider to be problematic for you in sexual life? A notetaker assisted the researcher in conducting the focus group discussions. After each individual or focus group interview, field notes with verbal and non-verbal cues, memos and preliminary interpretations were summarised to guide the subsequent interviews and research questions and to get first insights into data generated. The interviews were audio-recorded and transcribed verbatim.

Data analysis 
Informed by Framework Analysis [54, 55], data were analyzed in an iterative, analytical and inductive process of comparing and contrasting propositions and developing patterns and themes. This implied different steps which are familiarisation with data, identification of a thematic frame that served to index and chart all transcripts and allow for organizing, classifying, comparing and contrasting the extracted data. Mapping and interpretation are the last steps whereby the themes and subthemes were identified and structured in a meaningful manner supported by relevant information. The first steps of the analysis were done in Arabic, the native language of the participants. At the level of charting, we translated codes and data extracts into English and grouped them under headings and subheadings. The rationale for this was to preserve the cultural meaning conveyed by the language and the implications this might have on the accuracy of findings $[56,57]$.

\section{Rigour}

Credibility or internal validity of findings was checked through reflexivity that was facilitated by the use of an audit trail to keep methodological and analytic documentation, follow the thought processes, track all the decisions made and show transparency and rigour [55]. Transferability was achieved by the thick description of data that was provided through individual and focus group interviews with different purposeful samples chosen from different settings. Within a comfortable environment and good rapport, women extensively reflected on their thoughts and experiences, generating lengthy transcripts and detailed descriptions which are necessary for meaningful findings [56]. Dependability or reliability was ensured by required a meticulous and contextual analysis and interpretation of data. The three authors worked together to agree the coding and analysis process. They separately analyzed two transcripts that were translated into English by MA whose native language is Arabic. Moreover, all the selected accounts that were coded and extracted by MA, were translated into English, printed out and cut into different pieces; each piece, including only one quote without any label. They were sorted by the two other researchers, categorized under different themes and subthemes. Throughout the analysis process, the three researchers compared and discussed findings until consensus was achieved. We used various strategies to enhance the confirmability of findings. These included a transparent audit trail and peer debriefings.

\section{Results}

\section{Sample characteristics}

Fifty-two women aged between 40 and 55 years participated in the study. Their mean age was 47.40 years. All were married except for five women: one was single, three widowed and one divorced. Sixteen women had enrolled at university, fourteen had secondary education (grades 10-12), twelve had an intermediate education (grades 7-9) and ten had an elementary education (grades 1-6) or less. Twentyeight were housewives. Twenty-seven were Christians and the other Muslims, representing the two dominant religions in Lebanon. Twenty-five indicated that they had started the perimenopause or menopausal period. 


\section{Themes}

One-third of the participants reflected on difficult sexual experiences that made them unhappy and dissatisfied with their sexual life. Women in their majority did not define their sexual difficulties as physical or affected by menopause or ageing. Women's sexual difficulties were mainly induced by an inhibiting sexual education and a patriarchal marital relation that favours men's sexual rights and needs above women's. Relational problems and the burden of daily life were additional factors that overwhelmed women physically and psychologically and also altered their sexual life. In line with social norms, women expressed their sexual difficulties within the institution of marriage. Key themes in the onset and chronicity of women's sexual difficulties are Women's inability to communicate sexual desires and concerns; male-related sexual difficulties; marital conflicts; and sexual difficulties as context and time-bound. Sexual difficulties are explained and supported by the participants' quotations.

\section{Women's inability to communicate sexual desires and concerns}

Contained within this subtheme is the women's reflection on the challenges of experiencing themselves as sexual beings due to the absence of sexual education and no readiness to sexual life.

One cause of sexual problems is the absence of sexual education in Lebanon. This is so wrong. She does not know how to discover her body and how to enjoy with her husband. In our society, the woman is not at all aware of sexual life when she gets married. Her husband will not enjoy too. She takes time to discover her body (Faten, married in her 30s, university education, individual interview/II).

After many years of marriage, many women described their deep embarrassment, guilt feelings and shyness to see their husbands naked for the first time or to engage in penetrative sex. Thus, frigidity, vaginismus and forced sex were reported as the results. Carmen, a woman who had seven years of psychotherapy due to vaginismus, defined women's sexual difficulties as their inability to enjoy their body due to their inhibiting feelings. She said:

Here you have the taboos, I mean the interdictions, the no, the shame, and this is not allowed ... and until now, many women (single young women) do not know why things are not allowed. The shame and interdictions cause sexual frigidity and lead to problems with the husband after marriage because she is not allowed (to be sexually active) before marriage. Suddenly, she gets married, and everything becomes allowed... Psychologically, you are blocked. How she will do it in 24 hours? ... that is why there are a lot of sexual difficulties among women... (Carmen, 43 years, premenopause, university, II).

Ibtissam's husband forced himself on her during their first sexual intercourse while her mother and mother-in-law waited outside to make sure that things had gone successfully, and that the bride's virginity was confirmed. Kamal was another victim of sexual ignorance, although and like Ibtissam, she was a university student at the time of her marriage. Her first negative sexual experiences led to sexual disinterest throughout the long years of her marriage. Her negotiations with her husband to escape this 
'tough duty' as she called it, failed. Sexual intercourse was not pleasurable for her. It was just a marital duty done at the husband's request. She recounted:

I am the type who had an upbringing (conservative). When I got married, I told him: I will iron, wash and clean for you, but do not approach me. Imagine the extent to which we were shy and did not have this. Later on, he helped me get used to him progressively. These things (sex) are not important to me. I am not interested in this thing... I do not like (sex). I do it unwillingly. I am not happy with this... is the least of my worries. I don't like it. What is important to me is the way he treats me (Kamal, university, 55 years, menopause, II).

Many participants expressed the assumption that sexual difficulties are not female-related because there is a 'general assumption' that women are always 'ready to have sex.

The woman is stronger than the man in sex. A man might develop impotence and need to take medication... But I rarely hear of women taking these things. Maybe her hormones are stronger ... the woman does not have issues with her sexual life unless she is physically ill. A woman is always ready to respond to a man's needs (Sara, elementary, 49 years, premenopause, II).

Only one participant, Racha, frankly talked about her embarrassment or pain during sexual intercourse due to vaginal dryness. She was grateful of her husband's understanding attitude.

Now that I have no menses, a quite long time ago, I feel dryness. I mean... it is dry, this is embarrassing. I mean it hurts me, yes I have pain during sex. But my husband is so patient... Thank God... (Racha, secondary, 51 years, menopause, Focus Group/FG).

Racha's experience triggered, on the other hand, two women of the group to sadly reflect on their husbands' selfishness and sometimes ignorance of their needs.

\section{Male-related sexual difficulties}

This section focuses on women's definition of their sexual difficulties associated with their husband's 'poor sexual performance', specifically, erectile dysfunction and early ejaculation. They also accused their husbands of being selfish, not caring about their own sexual needs. Some women reported being forced to engage in anal sex. They furiously contested their husbands' sexual behaviour describing it as unpleasant and illegitimate, banned by the society and religion particularly by Islam. These problems had negative impacts on women's physical and psychological wellbeing. Ten women highlighted their sexual dissatisfaction due to their husbands' erectile and ejaculatory problems. Their embarrassment was exacerbated by their husbands' avoidance and lack of communication to manage the situation.

Mada, a 46-year menopausal woman with intermediate education who complained of her husband's erectile dysfunction, said: 
... Because he does not answer me, I say that there is no need to talk... There is no need at all; it makes no difference (whether I tell him or not)... I do not confront him... I feel that he avoids me because he has poor sexual performance... I ask him, but he never answers me. This is frustrating... So I avoid talking with him about these issues (Mada, intermediate, 46 years, menopause, II).

Mada stated that she and her husband had not had sex for the past year and did not even talk about it . During the interview, Mada looked desperate. The need to share her concerns was apparent, considering that her sexual difficulties impacted profoundly on her, physically and psychologically.

Some women interpreted their husbands' attitude and behaviour as sexual abuse and neglect. Yet, they felt powerless due to the lack of resources and the cultural norms that do not recognize their sexual rights. Women preferred to keep quiet and sacrifice at the expenses of their sexual satisfaction and overall wellbeing. They accepted their situation as their lot in life. As illustrated by Karine, a 43-yearwoman with limited formal education:

But what can a person do; in our community, once the woman gets married, it is finished. You get married, and you get children. You have tried to solve your problems, but you failed. What do you do? What is the solution? There are children. You have to sacrifice either your children or yourself. I sacrifice myself (Karine, elementary, 43 years, premenopause, II).

Karine reported on her endurance of her husband's sexual problems since the time she got married, 21 years ago. Being obedient to her husband, who warned her to keep his problem hidden, she was so cautious about discussing her case until she was firmly assured of the confidentiality of the interview.

Lana faced the same problem with her husband, whom she accused of sexual impotence. She expressed her rights for sexual pleasure and criticized the gender-based social norms that overlook women's sexual needs. She said:

The man sleeps with his wife and does nothing... You feel that you become used to that... He (her husband) enjoys it, and that is. It does not count if the woman enjoys or not. This is also my right, my right. If the situation was reversed ...., I do not think that he would have been patient... He would have blamed me 20 times. He would have cheated on me or married another woman ... But when the problem is from the man, you have to keep quiet (Lana, secondary, 50 years, perimenopause, II).

Despite her anger, Lana, like the majority of women, expressed her readiness to seek help to satisfy her husbands' sexual needs provided the situation was reversed.

But I am not keen (for sex), it is just for him (her husband); so that he does not say that I neglected him... If he likes it, no, I try; I try to do everything (to please him)... If my husband wants (sex) and I have sexual dysfunction, I treat myself. But if my husband is impotent, why do I have to treat myself?

Other women dared to discuss during the interview their husband's sexual behaviours that they found undesirable and painful, particularly the practice of forced and anal sex. As articulated by Sara: 
I told you when he goes beyond the limits and wants to have anal sex. These problems happen. I do not accept this because I am not an animal to be treated in this way. If he loves me, he has to take care of me so that I give him this thing from my heart and with love (Sara, elementary, 49 years, premenopause, II).

Sara noted that to prevent her husband's behaviour, she convinced him that anal sex is unhealthy and might cause him fatal infectious diseases. Yet, Zeina who faced the same problem was unable to change her husband's "sexual perversion" as she said; being economically independent, she stopped having sex with him. Zeina reported that her sexual deprivation resulted in psychosomatic problems that required psychotherapy.

I am a human being, like him, I have my feeling, my, my, my,... [silence], what can I say? Because of that, I am suffering. I can not ventilate; I cannot satisfy my needs. This caused me a lot of pain, everywhere in my body (with tears in her eyes), and anger (Zeina, secondary, 52 years, menopause, FG).

\section{Marital conflict}

Common in women's narratives was the perception of the spouses' relationship as central to their sexual difficulties. They complained of a pile-up of events that were difficult to handle with the husband, and that led to poor and ineffective communication between the two spouses. Marital conflicts hurt women and created negative feelings towards their husbands such as resentment, indifference and disgust. Believing in the interplay of the physical and psychological factors in sexual life, women asserted that sex could not be satisfying if it is not driven by emotions and mutual attention between the spouses. Feeling uncomfortable inhibits sexual desire and pleasure and engenders sexual difficulties. Sex becomes a duty and abuse for women.

One participant explained that from her perspective, sexual life is not only about penile penetration; otherwise, it becomes what she termed 'disgusting'. In the same vein, another woman declared that at the beginning of her marital life, sex was pleasurable. Presently and because of marital conflicts, she had feelings of rejection and anger towards her husband. She stopped caring for him and completely lost sexual desire and orgasm. This was also the case for Sally, who claimed her total sexual disinterest and frigidity as she does not love her husband.

By the way, sorry, I do not have any sexual desire. I do it only at his insistence-no way, impossible. I do not have the desire. There is no way that I feel like it. I do not love him (Sally, university, 49 years, premenopause, $F G)$.

Sally supposed that she would have had sexual desire if she was with another man, implying that sexual difficulties are relational rather than biological. The other women of the group supported Sally's opinion and gave testimonies of their sexual life to ascertain that "women could not be instinctively driven" as they said. Another example was illustrated by Quinana, who declared that the primary purpose of participating in the study was to talk about what she described as a 'miserable sexual life'. She described 
herself as an 'automated sex robot' for her husband, who she described as rude and abusive. She stated that every time she has sex, she hates herself more and more.

My husband makes me feel that I am only important for this thing (sex). Because of that, I hate sexual life. I need to feel that I am a woman and then take what you want... I accept everything, poverty, misery, taking care of the house, cooking food every day... but I need him to value my efforts and then you can take from me whatever you want. With a strong tone, she said: I give you; you do not take by yourself; I give you... This thing makes me sad... I do not have any rights... I like sex to happen with love... (Quinana, secondary, 40 years, menopause, II).

When asked about why Quinana continues to have sex with her husband, she replied that she obeys him; otherwise, he violently beats her in front of the children and seriously harms her. Lacking love and respect, she reflected on her situation with apparent bitterness and chagrin.

Uguette was another victim of her husband's moral, physical and sexual abuse. She courageously voiced her disappointment in front of women in one of the focus groups:

When you get married, you say that this is the person that I want to live with... get joy with him, and found a nice family... You devote yourself, body and soul; then you are confronted by the truth... The man you dreamed about disappointed you; you become disgusted with him... if he sleeps with you, you do not want him. You just want him to finish and leave you alone. This means that you are not happy, and sexual issues are inhibited... It is very important to feel that you are desired, to feel that you are a woman (Uguette, secondary, 54 years, menopause, FG).

Conscious of the violation of her sexual rights, Uguette described herself as a passive recipient who is filled and left like 'garbage'. Although she was the wage earner of the family, she 'sacrificed' herself for her children and refused to leave the house to avoid social stigma.

The husbands' reported egoism and selfish sexual behaviour exhausted women and increased their marital conflicts that, in turn, intensified their sexual difficulties.

Sexual difficulties happen if the man is self-centred and wants to enjoy himself without caring about his wife... the man does not control himself... the insistence on his wife to always have sex just for himself... it is very important that the woman enjoys... This is in his nature; he does not care about his wife if she enjoys or not... Another issue relates to man insistence to have sex regularly ignoring her fatigue and concerns... His instincts drive man. In the majority of sexual relationships, women do not enjoy. It is all about the psychological context of the sexual relation (Dalia, university, 46 years, premenopause, II).

In the same line, Tressy said:

Life is not fair. It is the power of the stronger. My husband is not at all like this. In the end, you are tired, and you lose your interest. You become unhappy with sex, with everything. Your life is affected. Sex is not just an act; just a duty?! no... (Tressy, intermediate, 45 years, premenopause, FG). 


\section{Sexual difficulties as context and time-bound}

In this subtheme, sexual difficulties are framed within the challenges women face in their daily life as wives, mothers and workers in addition to personal health issues. These overwhelm them and limit their sexual interest and pleasure. For instance, Tamara, who is the only breadwinner of the family, explained:

If I have poor sexual performance, this does not mean that I do not want (to have sex). The problems of life are enormous, and you reach a point where you are tired... Social, financial and family burdens affect it (sexual life) without doubt and cause sexual difficulties. You need suitable conditions to accept the other... I often experience these situations... (Tamara, university, 49 years, perimenopause, FG).

In the same line, a conversation was initiated between two women of another focus group by saying:

Tressy. So, at some point, if nothing is happening between man and woman [meaning sex], I don't know if it is caused by poverty or worries ... (Tressy, intermediate, 45 years, premenopause, FG)

Sally approved Tressy's opinion. She said:

As for me, anything in the society, like what she said, the money, anything may affect me. My husband! No, no way! Nothing can affect him. As for me, if he does not work for one day, I am troubled... (Sally, university, 49 years, perimenopause, $F G$ ).

Sally added:

If my daughter is sick, I get troubled. Anything can make me nervous. So no way (making sex).

Tressy continued by saying:

Sexual life fades between the spouses. There is boredom, quarrel, and sexual life fades with the burden of life.

Reproductive health burdens like delivery, breastfeeding and infertility problems might also cause sexual difficulties. Mirvat, who has been facing infertility problems for seven years, said:

The feeling that you have put in the extra effort at the expense of your psychological status to stimulate the desire of your husband who himself might arrive from his work hungry and not in the mood because the timing is right. This is one of the worst things that might happen in marital life... At this moment, (she stopped talking and then in a hesitant voice said) I feel destroyed and often (she cries) I have uncontrollable crying when I finish (Mirvat, university, 41 years, premenopause, FG).

Mirvat's account was quite compelling and made all women in the focus group sympathize with her; they gave her advice to reduce her distress.

Another aspect of women's sexual difficulties was exemplified by Rayan who complained of an altered body-image and low self-esteem due to excessive weight gain. Such a portrayal that is dissonant with 
the idealized image of women's body triggered her negative feeling about herself and affected her sexual desire and capacity to satisfy her husband's sexual needs. This, in turn, made her more frustrated. She reported that:

I am upset because I feel sad; I cannot wear what I want. I do not like to sleep with my husband a lot. I pretend that I am tired. I am intimidated because of my obesity. This bothers me. I have been in this way for 5 to 6 months. I can't wait anymore. He used to enjoy it, but I didn't. My husband is still young, only 50 years old (Rayan, elementary, 45 years, premenopause, II).

\section{Discussion}

This study explored the perception and experience of sexual difficulties for the middle-aged Lebanese women and the way they are shaped drawing upon the individual and focus group interviews. Findings reveal that sexual difficulties are not always biologically driven and are rarely located solely at an individual level. While aspects within any particular woman may induce sexual difficulties, these are the results of a multitude of factors that are intra-personal, interpersonal and contextual. The complexity inherent to sexual difficulties further challenges their medicalized definition and supports the 'New View' model of women's sexual difficulties [58].

Due to the lack of awareness, many women in the study were unable to communicate their sexual desire and concerns at marriage. They were sexually awkward and had unpleasant sexual experiences. The failure to recognize the cues of sexual arousal might be attributed to sexual inhibition [59]. This has limited their ability to get actively engaged in sex with their partner. This had the consequence that both would misunderstand each other and be irresponsive towards each other's needs. Many of these women were in their thirties and highly educated at marriage but were unable to overcome their sexual inhibition. The lack of sexual competence at the first sexual intercourse alters women's sexual interest [60]. This specifically applies to women more than men, which further confirms the contextual aspect of women's sexuality [60]. As an example, one participant has suffered from vaginismus for many years. Although she is a psychologist, she attributed her problem to biological causes amenable to medical treatment and dismissed that the problem mainly resulted from an inhibiting sexual-self. Lacking knowledge and being inexperienced, she realized her problem only after two years of suffering. Sexual problems being not commonly discussed or associated with physical health conditions, women are less likely to promptly identify them. A qualitative study by Bellamy and colleagues [61] suggests that women's understandings of sexual problems resonate within the medical frame. The authors argued that 'problems arising from psychological difficulties were not seen as real problems and more akin to a good excuse' [61, p. 3242].

Women in this study did not perceive sexual difficulties as female related; these are male-related. For instance, one participant declared that woman does not develop sexual problems and is always ready to have sex. Many held men responsible for their problems accusing them of poor sexual performance and neglect of their wives. This might explain why only one woman affirmed the presence of vaginal dryness that caused her painful penetrative sex [dyspareunia] even though during the interviews, nearly half of 
them had entered the menopausal period. Menopause is still associated with an end of sexual activity in the Lebanese context. Sexual concerns or symptoms may be masked by this reductionist sociocultural understanding. Thus, many genuine sexual concerns of women remain unaddressed. At this time in their life, women have a general thought that they are unattractive and asexual as their femininity is lost [62; 63]. They develop a negative attitude towards sex and be ashamed of being sexually active [5]. Adding to that, in patriarchal societies, women cannot talk about their sex life as this is a taboo and private topic $[52,64]$. Another assumption could be that women are silent about their sexuality to hide their sexual problems.

Women described how erectile and ejaculatory problems and unpleasant sexual behaviours such as forced anal sex affected their sexual satisfaction. Previous studies reported these findings as significant risk factors of female sexual problems [9] like orgasmic and lubrication difficulties [65] and sexual disinterest and dissatisfaction $[66,67]$.The male-centric view dominates women's sexual life. Typically, sexual fulfilment is genitally focused $[59,68]$. Women are socialized to act based on their social gender, perpetuating a perception of sexual life as equivalent to vaginal-penile intercourse. This predominant misconception about normative heterosexuality is a challenge for men and women when they have poor performance. Women's capacity to negotiate sexual fulfilment away from the genitally focused sexual behaviour and the 'imperative' is fundamental.

For women in this study, sexual distress was reinforced by their husbands' reported resistance to admit the men's sexual problems and seek help. Rather than voicing their concerns, they silently shoulder their husbands' burden as their lot in life and accord particular attention to their husbands' ego at the expense of their wellbeing. A paradox surfaces between women's portrayal as sexually passive and submissive and their responsibility to protect their husbands of social stigma as their sexual performance is equated with their masculinity. Women might also interpret men's poor sexual performance as their failure questioning their femininity and seducing capacities. As also revealed in previous studies, findings suggest that gender imbalance of power reinforces women's devotion and sacrifice for their partners [45, 52].

Anal sex does not correspond to women in this study to the 'real sex' as internalized and shaped by the sociocultural rules. This behaviour -defined in Islam as a perversion- appears to be of particular concern for Muslim women; it is illegitimate and justifies the divorce. Thus, women face sexual difficulties because they have sex they do not want but are unable to refuse it for relational and sociocultural reasons. Because of gender inequalities, the study findings indicate that some women devote themselves to their husbands, creating emotional and sexual concerns and confusions $[61,69]$.

The quality of the relationship is essential to women's experience of sexual difficulties. Intercourse by itself is not the aim for women. Their perception of the relational context and the quality of the communication with the partner seem to be strongly associated with their sexual interest [60]. Love, romance, intimacy trigger sexual desire $[40,70]$. Thus, marital conflicts is another contributing factor to women's sexual difficulties. Otherwise, they perceive themselves as sexual objects for their husbands' 
pleasure as well as victims of their moral, physical and sexual abuse. Women's expectations about sex is linked with sexual interest [60]. This confirms that women's sexuality is not only genitally focused but multidimensional. Basson $[71,72]$ suggests that sexual life and intimacy are mutually dependent as one affects the other; when sexual activity does not provide women with affection, they are not encouraged to have sex. The claim of some women in this study that sexual life is not worth the price if the marital relationship is not good is supported by other qualitative $[61,73]$ and quantitative research $[74,75]$.

The violation of women's ideals inhibits their feelings, mutes their sexuality and produces sexual problems and dissatisfaction. Appropriate communication between partners has a positive effect on the quality of their relationship. Positive relationship quality, in turn, increases sexual satisfaction.

Women's sexual difficulties are context and time-bound. Being overwhelmed by daily life events and stressors affects their ability to feel sexual as was also confirmed by Bellamy and colleagues' study [61]. In a list of pressing needs, they tend to relegate their sexuality to a second plan. According to Maslow's 'Hierarchy of Needs' (1943), sexual fulfilment is difficult to achieve given other priorities. Another finding that recognizes the multidimensional framework of sexual difficulties is the interference of women's reproductive concerns [breastfeeding and infertility] and psychological problems [low body-image and depressive symptoms] with their sexual interest and pleasure. In a heterosexual relation, concern about body image, weight, attractiveness, physical and psychological conditions and general wellbeing affect women's sexual functioning and satisfaction $[76,77]$.

\section{Limitations}

The study findings are based on a sample of middle-aged women who identified themselves as heterosexual, and the majority was married. Because of the constraint around sexual disclosure, some women expressed their apprehension, uncertainty and timidity concerning the topic. It is plausible that women with other characteristics did not want to share their sexual concerns. So, other aspects of women's sexuality, including sexual orientation and sex outside marriage, may not have been captured. We do not claim to generalize findings to the wider women population. Yet, findings enrich the social science literature about a sensitive topic that is poorly discussed, particularly among middle-aged women generally and in Lebanon specifically. The use of a vignette in the first interviews was necessary to break the taboo around sexuality a limitation though is it might have induced hypothetical data. Nevertheless, the vignette served to prompt women to talk about and reflect on their experiences and perspectives, adding something new to the literature. This was enhanced by the use of both individual and focus group interviews. The data analysis was performed separately for each method using the same process. In the final step of the analysis individual and group data were combined without privileging one method over another $[51,78]$. Another limitation was 'meaning' lost in the translation process despite efforts to maximize accuracy.

\section{Conclusion}


Findings of this study provide further evidence of the New View' model that defines female sexual difficulties based on a comprehensive framework that calls for diversity and openness to women's perception of their sexual difficulties. This study has implications on the contemporary understanding of women's sexual difficulties that could not happen in a vacuum and could not be isolated of the biological, relational power, psychological, cultural and other contextual factors. Women in this study voiced their sexual difficulties from a feminist perspective that considers their views as fundamental. In this way, health professionals should recognize the multidimensional nature of women's sexual difficulties and develop their knowledge and skills to appropriately respond to women's concerns. It is erroneous to limit women's sexual difficulties to a biological cause that could be alleviated by a pharmaceutical drug and neglect all other related factors. A comprehensive sexual education should be offered to all people with different age groups and backgrounds to recognize the cues and importance of sexual life and know how to manage it. It should mainly target the couples given the impact of their interrelation on one another sexual satisfaction. The first sexual experiences tend to shape later experiences, particularly for women [60]. The latter should be mainly targeted to understand and voice their sexual needs and rights, and men to be attentive and responsive to theirs. More studies are needed using qualitative designs to generate further information grounded in women's context considering different age groups, sexual orientations and marital statuses.

\section{Abbreviations}

GSSAB: Global Study of Sexual Attitudes and Behaviors; Il: Individual Interview; FG: Focus Group.

\section{Declarations}

\section{Ethics approval and consent to participate}

At every step of the research process, the researchers carefully attended to the ethical considerations associated with any research and particularly that on a sensitive issue. Ethical approval was obtained from the Research Committee/Institutional Review Board at the University of Balamand and Saint Georges Hospital University Medical Centre. Another one was obtained from Rafik Hariri University Medical Centre. These two medical centers served to recruit clinical cases. Before they participated in the study, all participants received an information letter guaranteeing that conditions of dignity and confidentiality and anonymity of all forms of data generated are met. They were informed about their voluntary involvement in the study and their right to withdraw at any time. They also signed informed consent. Very few of them consented verbally by fear of providing a written consent particularly that the study topic is very sensitive. In addition, a written consent might be culturally seen as a lack of trust. The interviews were audio-recorded with the participants' consent. All transcripts were identified by pseudonyms and were securely stored in a locked file cabinet. The participants were assured that nobody would have access to the raw data other than the researchers of the study. However, they clearly understood that the results will be disseminated through conferences and publications. 
As part of the informed consent, all participants were aware that the results will be published. Accordingly, the majority provided a written consent and few of them preferred to consent verbally.

\section{Availability of data and material}

Study participants consented to data sharing only with the research team, and not for additional data use purposes. This is in line with current GDPR legislation. Further, the contextual sensitivity of the data may identify study participants and place them at risk.

\section{Competing interests}

The authors declare that they have no competing interests.

\section{Funding}

Not applicable

\section{Authors' contributions}

All three authors made substantial contributions to the development of this manuscript. They provided valuable conceptual and technical input from the conception to the conclusion of the study. MA designed the topic guide in consultation with CBJ and TK. She conducted data collection and transcription. MA, CBJ and TK were involved in data analysis. MA drafted the manuscript, and all authors have critically revised it. CBJ and TK edited the manuscript and verified the language of the text. The three authors approved the final version.

\section{Acknowledgements}

We would like to express our gratitude to the participants who had voluntarily accepted to provide their insights concerning their sexual difficulties. We are also thankful to the administrators of the centres who provided us with their support to get access to the participants.

\section{References}

1. DeLamater J, Koepsel ER, Johnson T. Changes, changes? Women's experience of sexuality in later life. Sex Relatsh Ther. 2019;34:211-27.

2. Hinchliff S, Tetley J, Lee D, Nazroo J. Older adults' experiences of sexual difficulties: Qualitative findings from the English longitudinal study on ageing (ELSA). J Sex Res. 2018;55:152-63.

3. Lo SS, Kok WM. Sexual Behavior and Symptoms among Reproductive Age Chinese Women in Hong Kong. J Sex Med. 2014;11:1749-56.

4. Clayton AH, Juarez EM. Female sexual dysfunction. Psychiatric Clinics. 2017;40:267-84. 
5. Jamali S, Javadpour S, Mosalanejad L, Parnian R. Attitudes about sexual activity among postmenopausal women in different ethnic groups: a cross-sectional study in Jahrom, Iran. J Reprod Fertil. 2016;17:47.

6. Obermeyer CM, Reher D, Saliba M. Symptoms, menopause status, and country differences: a comparative analysis from DAMES. Menopause. 2007;14:788-97.

7. Ishak IH, Low WY, Othman S. Prevalence, risk factors, and predictors of female sexual dysfunction in a primary care setting: a survey finding. J Sex Med, 2010;7:3080-7.

8. Nicolosi A, Laumann EO, Glasser DB, Moreira Jr ED, Paik A, Gingell C. Sexual behavior and sexual dysfunctions after age 40: the global study of sexual attitudes and behaviors. Urology. 2004;64:9917.

9. Zhang H, Yip PS. Female sexual dysfunction among young and middle-aged women in Hong Kong: Prevalence and risk factors. J Sex Med. 2012;9:2911-8.

10. Dennerstein L, Randolph J, Taffe J, Dudley E, Burger H. Hormones, mood, sexuality, and the menopausal transition. Fertil steril. 2002;77:42-8.

11. Gracia CR, Sammel MD, Freeman EW, Liu L, Hollander L, Nelson DB. Predictors of decreased libido in women during the late reproductive years. Menopause. 2004;11:144-50.

12. Nazarpour S, Simbar M, Tehrani FR. Factors affecting sexual function in menopause: A review article. Taiwan J Obstet Gyne. 2016;55:480-7.

13. McCool-Myers M, Theurich M, Zuelke A, Knuettel H, Apfelbacher C. Predictors of female sexual dysfunction: a systematic review and qualitative analysis through gender inequality paradigms. BMC women's health. 2018;18:1-15.

14. Moreira Jr ED, Brock G, Glasser DB, Nicolosi A, Laumann EO, Paik A, Wang T, Gingell C, GSSAB Investigators' Group.. Help-seeking behaviour for sexual problems: The global study of sexual attitudes and behaviors. International journal of clinical practice. 2005;59:6-16.

15. Laumann EO, Paik A, Glasser DB, Kang JH, Wang T, Levinson B, Moreira ED, Nicolosi A, Gingell C. A cross-national study of subjective sexual well-being among older women and men: findings from the Global Study of Sexual Attitudes and Behaviors. Archives of sexual behavior. 2006;35:143-59.

16. Nicolosi A, Laumann EO, Glasser DB, Moreira Jr ED, Paik A, Gingell C. Sexual behavior and sexual dysfunctions after age 40: the global study of sexual attitudes and behaviors. Urology. 2004 Nov 1;64:991-7.

17. Mitchell KR, Mercer CH, Ploubidis GB, Jones KG, Datta J, Field N, Copas AJ, Tanton C, Erens B, Sonnenberg P, Clifton S. Sexual function in Britain: findings from the third National Survey of Sexual Attitudes and Lifestyles (Natsal-3). The Lancet. 2013;30:1817-29.

18. Gracia CR, Freeman EW, Sammel MD, Lin H, Mogul M. Hormones and sexuality during transition to menopause. Obstetrics \& Gynecology. 2007;109:831-40.

19. DeLamater J, Karraker A. Sexual functioning in older adults. Curr Psychiat Rep. 2009;11:6-11. 
20. Hinchliff S, Gott M. Challenging social myths and stereotypes of women and aging: Heterosexual women talk about sex. J Women Aging. 2008;20:65-81.

21. Dillaway HE. Menopause is the 'good old' women's thoughts about reproductive aging. Gender Soc. 2005;19:398-417.

22. Beckman N, Waern M, Gustafson D, Skoog I. Secular trends in self reported sexual activity and satisfaction in Swedish 70 year olds: cross sectional survey of four populations, 1971-2001. Bmj. 2008;337:a279.

23. Lee DM, Nazroo J, O'Connor DB, Blake M, Pendleton N. Sexual health and wellbeing among older men and women in England: Findings from the English Longitudinal Study of Ageing. Arch Sex Behav. 2016;45:133-44.

24. Lee DM, Vanhoutte B, Nazroo J, Pendleton N. Sexual health and positive subjective wellbeing in partnered older men and women. Journals of Gerontology Series B: Psychological Sciences and Social Sciences. 2016;71:698-710.

25. Berra M, De Musso F, Matteucci C, et al. The impairment of sexual function is less distressing for menopausal than for premenopausal women. J Sex Med. 2010;7:1209-

26. Nosek M, Kennedy HP, Gudmundsdottir M. Distress during the menopause transition: a rich contextual analysis of midlife women's narratives. Sage Open. 2012;2:2158244012455178.

27. Abadi OS, Cheraghi MA, Tirgari B, Nayeri ND, Rayyani M. Feeling an Invisible Wall: The Experience of Iranian Women's Marital Relationship After Surgical Menopause: A Qualitative Content Analysis Study. J Sex Marital Ther. 2018; doi: 10.1080/0092623X.2018.1440451.

28. Jaafarpour M, Khani A, Khajavikhan J, Suhrabi Z. Female sexual dysfunction: prevalence and risk factors. Journal of clinical and diagnostic research: JCDR. 2013;7:2877.

29. American Psychiatric Association. Diagnostic criteria from dsM-iV-tr. American Psychiatric Pub; 2000.

30. Diagnostic AP. statistical manual of mental disorders: DSM-5 $5^{\text {TM }}$. Arlington. VA American Psychiatric Publishing. 2013.

31. Chedraui P, Pérez-López FR. Assessing sexual problems in women at midlife using the short version of the female sexual function index. Maturitas. 2015;82:299-303.

32. Chedraui P, Pérez-López FR, Mezones-Holguin E, San Miguel G, Avila C, Collaborative Group for Research of the Climacteric in Latin America (REDLINC. Assessing predictors of sexual function in mid-aged sexually active women. Maturitas. 2011;68:387-90.

33. Kadri N, Alami KM, Tahiri SM. Sexual dysfunction in women: population based epidemiological study. Archives of women's mental health. 2002;5:59-63.

34. Elnashar AM, EL-Dien Ibrahim M, El-Desoky MM, Ali OM, El-Sayd Mohamed Hassan M. Female sexual dysfunction in Lower Egypt. BJOG: An International Journal of Obstetrics \& Gynaecology. 2007;114:201-6. 
35. Hassanin IM, Helmy YA, Fathalla MM, Shahin AY. Prevalence and characteristics of female sexual dysfunction in a sample of women from Upper Egypt. International Journal of Gynecology \& Obstetrics. 2010;108:219-23.

36. El Shafie K, Al Farsi Y, Al Zadjali N, Al Adawi S, Al Busaidi Z, Al Shafaee M. Menopausal symptoms among healthy, middle-aged Omani women as assessed with the Menopause Rating Scale. Menopause. 2011;18:1113-9.

37. Jamali S, Javadpour S, Mosalanejad L, Parnian R. Attitudes about sexual activity among postmenopausal women in different ethnic groups: a cross-sectional study in Jahrom, Iran. Journal of reproduction \& infertility. 2016;17:47-55.

38. Maaita ME, Khreisat BM, Tasso OA, Otom NN, Aljaafreh BM, Abuassaf GM. Prevalence and associated risk factors of female sexual dysfunction among Jordanian women. Journal of family medicine and primary care. 2018;7:1488-1492.

39. Obermeyer CM, Reher D, Saliba M. Symptoms, menopause status, and country differences: a comparative analysis from DAMES. Menopause. 2007;14:788-97.

40. Azar M, Kroll T, Bradbury-Jones C. Lebanese women and sexuality: A qualitative inquiry. Sexual \& Reproductive Healthcare. 2016;8:13-8.

41. Denzin NK, Lincoln YS. The sage handbook of qualitative research. 3rd ed. Thousand Oaks, CA: Sage Publications; 2005.

42. Barbour R. Introducing qualitative research: a student's guide. Sage; 2013.

43. Graffy J, Grant J, Boase S, Ward E, Wallace P, Miller J, et al. UK research staff perspectives on improving recruitment and retention to primary care research; nominal group exercise. Fam Pract. 2008;26:48-55.

44. Howatson-Jones IL. Dilemmas of focus group recruitment and implementation: a pilot perspective. Nurse Researcher. 2007;14:7-17.

45. Obermeyer CM, Reher D, Alcala LC, Price K. The menopause in Spain: results of the DAMES (Decisions At MEnopause) study. Maturitas. 2005;52:190-8.

46. Shifren JL, Monz BU, Russo PA, Segreti A, Johannes CB. Sexual problems and distress in United States women: prevalence and correlates. Obstet Gynecol. 2008;112:970-8.

47. Given LM, editor. The Sage encyclopedia of qualitative research methods. Sage publications; 2008.

48. Hautamäki K, Miettinen M, Kellokumpu-Lehtinen PL, Aalto P, Lehto J. Opening communication with cancer patients about sexuality-related issues. Cancer Nurs. 2007;30:399-404.

49. O'reilly M, Parker N. 'Unsatisfactory Saturation': a critical exploration of the notion of saturated sample sizes in qualitative research. Qual Res. 2013;13:190-7.

50. Walker JL. Research column. The Use of Saturation in Qualitative Research. Canadian Journal of Cardiovascular Nursing. 2012;22:37-41.

51. Lambert SD, Loiselle CG. Combining individual interviews and focus groups to enhance data richness. Journal of advanced nursing. 2008;62:228-37. 
52. Bradbury-Jones C, Taylor J, Herber OR. Vignette development and administration: a framework for protecting research participants. Int J Soc Res Method. 2014;17:427-40.

53. King A, Hoppe RB. "Best practice" for patient-centered communication: a narrative review. Journal of graduate medical education. 2013 Sep;5(3):385-93.

54. Ritchie J, Spencer L. Qualitative data analysis for applied policy research. In: Bryman A, Burgess, A, editors. Analysing qualitative data. London: Routledge; p. 173-194.

55. Ward DJ, Furber C, Tierney S, Swallow V. Using Framework Analysis in nursing research: a worked example. J Adv Nurs. 2013;69:2423-31.

56. Polkinghorne DE. Language and meaning: Data collection in qualitative research. J Couns Psychol. 2005;52:137.

57. Al-Amer R, Ramjan L, Glew P, Darwish M, Salamonson Y. Language translation challenges with Arabic speakers participating in qualitative research studies. International journal of nursing studies. 2016;54:150-7.

58. Kaschak E, Tiefer L. A new view of women's sexual problems. Routledge; 2014 Feb 25.

59. Basson R. A model of women's sexual arousal. J Sex Marital Ther. 2002;28:1-0.

60. Graham, C.A., Mercer, C.H., Tanton, C., Jones, K.G., Johnson, A.M., Wellings, K. and Mitchell, K.R., 2017. What factors are associated with reporting lacking interest in sex and how do these vary by gender? Findings from the third British national survey of sexual attitudes and lifestyles. BMJ open, $7(9)$.

61. Bellamy G, Gott M, Hinchliff S. Women's understandings of sexual problems: findings from an indepth interview study. J Clin Nurs. 2013;22:3240-8.

62. Ussher JM, Perz J, Parton C. Sex and the menopausal woman: A critical review and analysis. Feminism \& Psychology. 2015 Nov;25(4):449-68.

63. Abadi OS, Cheraghi MA, Tirgari B, Nayeri ND, Rayyani M. Feeling an invisible wall: The experience of Iranian women's marital relationship after surgical menopause: A qualitative content analysis study. Journal of Sex \& Marital Therapy. 2018 Oct 3;44(7):627-40.

64. Janghorban R, Latifnejad Roudsari R, Taghipour A, Abbasi M, Lottes I. The shadow of silence on the sexual rights of married Iranian women. BioMed research international. 2015;2015:1-12.

65. Oberg K, Sjögren KF. On Swedish women's distressing sexual dysfunctions: some concomitant conditions and life satisfaction. J Sex Med. 2005;2:169-80.

66. Deeks AA, McCabe MP. Sexual function and the menopausal woman: The importance of age and partner's sexual functioning. J Sex Res. 2001;38:219-25.

67. Fisher WA, Rosen RC, Eardley I, Sand M, Goldstein I. Sexual experience of female partners of men with erectile dysfunction: the female experience of men's attitudes to life events and sexuality (FEMALES) study. J Sex Med. 2005;2:675-84.

68. Nicolson P, Burr J. What is 'normal' about women's (hetero) sexual desire and orgasm?: a report of an in-depth interview study. Social Science \& Medicine. 2003;57:1735-45. 
69. Cacchioni T. Heterosexuality and 'the labour of love': A contribution to recent debates on female sexual dysfunction. Sexualities. 2007;10:299-320.

70. Brotto LA, Heiman JR, Tolman DL. Narratives of desire in mid-age women with and without arousal difficulties. Journal of sex Research. 2009;46:387-98.

71. Basson R. The female sexual response: A different model. J Sex Marital Ther. 2000;26:51-65.

72. Basson R. Using a different model for female sexual response to address women's problematic low sexual desire. J Sex Marital Ther. 2001;27:395-403.

73. Ayling K, Ussher JM. 'If sex hurts, am I still a woman?' The subjective experience of vulvodynia in heterosexual women. Arch Sex Behav. 2008;37:294-304.

74. Bancroft J, Loftus J, Long JS. Distress about sex: A national survey of women in heterosexual relationships. Arch Sex Behav. 2003;32:193-208.

75. Tehrani FR, Farahmand M, Simbar M, Afzali HM. Factors associated with sexual dysfunction; a population based study in Iranian reproductive age women. Arch Iran Med. 2014;17:679-84.

76. Dove NL, Wiederman MW. Cognitive distraction and women's sexual functioning. J Sex Marital Ther. 2000 Jan 1;26(1):67-78.

77. Pujols Y, Meston CM, Seal BN. The association between sexual satisfaction and body image in women. J Sex Med. 2010;7:905-16.

78. Duggleby W. What about focus group interaction data? Qualitative health research. 2005 Jul;15:83240. 